\title{
Modular Training System as a Factor of Improving Educational Process
}

\author{
Mazlitdinova Dilnoza, Suyunova Maftuna, Khaydarova Guzalkhon, Saibnazarova Makhliyo, \\ Kodirova Maftuna
}

\begin{abstract}
At present, a new concept of industrial production is being implemented in Uzbekistan. The continuous process of updating equipment and technology places high demands on the training of specialists in the field of preparing future foreign language teachers. In modern scientific, technical and socioeconomic conditions, the main requirement for professional training of a specialist is the guarantee of the formation of a clearly defined level of professional competence. This inevitably entails a change in traditional educational technologies, in which it is impossible to assess the potential learning outcome. As a fundamental one, we accept the provision that the main, achievable goal of the functioning of the professional education system is to build the competence of a specialist, which also includes the development of professional qualities of his personality. Thus, the formulated goal of vocational training, in our opinion, is more consistent with the real requirements and conditions of production. The universally noted goal-setting as an orientation to the training of highly qualified specialists who are fluent in their chosen profession remains at the level of declarations, without changing the real situation in practice.

The article on modular training analyzes the integration of the principles of modularity, self-organization and context that can guarantee the formation of a certain level of professional competence of future specialists, which determines the relevance of the chosen scientific direction of research.
\end{abstract}

Keywords The module; the principle of activity; the principle of listening and equality; the principle of problem; the principle of cognitive visualization; the principle of reliance; the principle of motivation; the principle of modularity; technology; modular training; module training program.

\section{INTRODUCTION}

Applying modeling methods, a method of system analysis of teaching FL, having studied in domestic and foreign experience in training specialists in the field of theoretical methodology of teaching foreign languages, we came to the conclusion that the achievement of this training goal can be achieved by integrating the following leading factors: modularity, self-organization, context and building on this

Revised Manuscript Received on 14, October 2019.

Mazlitdinova Dilnoza, Seniour lecturer, National University of Uzbekistan named after Mirzo Ulugbek Faculty of foreign philology, Uzbekistan. (Email: d.mazlitdinova@nuu.uz)

Suyunova Maftuna, lecturer, National University of Uzbekistan named after Mirzo Ulugbek Faculty of foreign philology, Uzbekistan. (Email: m.suyunova@nuu.uz)

Khaydarova Guzalkhon, lecturer, National University of Uzbekistan named after Mirzo Ulugbek Faculty of foreign philology, Uzbekistan. (Email: g.haydarova@nuu.uz)

Saibnazarova Makhliyo, lecturer, National University of Uzbekistan named after Mirzo Ulugbek Faculty of foreign philology, Uzbekistan.(Email: m.saibnazarova@nuu.uz)

Kodirova Maftuna, lecturer, National University of Uzbekistan named after Mirzo Ulugbek Faculty of foreign philology, Uzbekistan.(Email: m.qodirova@nuu.uz). basis, a new pedagogical technology aimed at guaranteed formation of professional competence of a specialist.

A retrospective of the development of the didactic system of modular training allows us to conclude that programmed teaching served as the primary basis of this pedagogical phenomenon. Against the background of the structure of programmed training, the contours of modular technologies are visible. Programmed training is based on the principles of dividing training material into small doses; a clear definition of the boundary fragments of the educational content, immediate confirmation of the assimilation of knowledge, the presence of direct and feedback, the possibility of an objective solution to control problems; the introduction of elements of self-control by students; individualized learning opportunities. The effectiveness of programmed instruction has been convincingly proved in the works of domestic and foreign scientists [1, 2, 22]. The improvement of programmed instruction led to the emergence of a block method of instruction developed by Polish scientists (Ch. Kupisevich et al.) [4].

Modern conditions impose high requirements on the level of professionally important qualities of a specialist. In the conceptual apparatus of professional pedagogy, the main indicator of a specialist's qualification level is recognized as his professional competence. The term "competency" serves as a link between the components of the traditional triad of "knowledge, skills." Professional pedagogy interprets competence as "in-depth knowledge of a subject or a mastered skill" [5, p. 32]. Competence differs from perfection in its level: competence is more real, one might say, a more mundane goal. "Perfection is both the absolute state of achievement and the highest level of functioning achieved by few in relation to the majority." [14, p.25]. Competence is a complex concept; it includes both the content - (knowledge) and the process components (skill). A competent specialist should understand the essence of the problem and be able to solve it practically. Competence involves the possession of information to successfully solve professional problems in these conditions. Competence is a state of adequate performance of a task. Moreover, in contrast to excellence, competence "usually cannot be compared. A person is either competent or not competent in relation to the required level of performance, and not in relation to the achievements of others" [2, p.6]. This unambiguity in the interpretation of the concept of "competency", presented as "the ability to actual performance of activities", allows you to use it as the goal of 
the functioning of the training system. Achieving this goal requires the development of appropriate training technology.

\section{MATERIALS AND METHODS}

The work used a combination of theoretical and empirical research methods. These include: scientific analysis of sources on the issue under consideration, which made it possible to formulate the initial positions of the study; analysis of the results of educational activities of students; pedagogical experiment; questioning; monitoring of student activities in practical classes.

\section{LITERATURE REVIEW}

The modular approach, as an effective learning system, noted Yu.K. Balashov and V.A. Ryzhov based on the analysis of professional training in developed countries [19]. At the same time, as the peculiarities of modular training, the authors highlight the presentation in foreign practice of a module as a certain amount of educational information necessary for the performance of any specific professional activity.

The popularity of modular education in higher educational institutions of developed countries stimulates interest in the state of the problem of the theory of instruction in this pedagogical direction. The study of foreign literature shows that the most important for the learning outcomes by foreign authors is given to structuring the content of training in the conditions of modular technology. So J. Russell characterizes the structure of the module as a set of autonomous portions of educational material. Such a construction of the module makes it possible to individualize learning by creating, in the opinion of J. Russell, "alternative modules" that ensure the adaptation of educational material in accordance with the abilities and interests of students [17].

A further development of the modular teaching was its variation, which received control functions. The next step in improving belongs to Postlthwait S.N. He proposed the concept of units of learning content, originally called "micro-courses" by him. According to this concept, an insignificant part of the training material could have the status of autonomous and included in the curriculum. Thus, the new concept of units of learning content merged with the system of programmed learning and received the name "modular learning technology." Modular technology has gained great popularity in universities in the United States, Germany, England and other countries. The generalized pedagogical experience of modular teaching of the initial period of its development is presented in the works of J.D. Russell, B. Goldschmidt and M. Goldschmidt. [15], [17]. These authors, recognized by the founders of modular learning, emphasize in their writings the importance of activating students in the pedagogical process, which indicates the alternative modular technology to traditional learning, in which passive knowledge is presented to the learner.

P.Yutsyavichene succeeded in combining progressive pedagogical ideas of foreign and domestic researchers. The analysis of theoretical and practical experience allowed her to formulate the backbone principles of modular training
[13] Since that moment, modular training has received the status of a combined didactic system. The principles of modular technology are not opposed to the general didactic, but as it were represent their new facets that open in the light of a different organization of the educational process. The modular approach is a natural result of the evolution of pedagogical theory, which is due to the logic of the development of the social system and scientific and technological progress. (N.B. Lavrentieva, A.I. Uman, M.A. Choshanov). Over the past two decades, the idea of modular learning has allowed the formation of a definite direction of psychological and pedagogical theory. A modular approach to the design of the content of teaching pedagogy is considered by N.B. Lavrentiev [7], [8], [9], [10].

The problems of transferring from the traditional model of the educational process organization to the modular teaching technology in high school are analyzed by P.I. Tretyakov and I. B. Sennovsky [20], [23].

The influence of modular learning on the underlying mental processes that make up the nature of personal selfdevelopment is analyzed by K. Ya. Vazina [21]. Noting the problems of human self-development K.Ya. Vazina points to the biosocial organization of an individual caused by two life programs: social, controlled by consciousness and biological, controlled by subconscious and physiology. The activity of consciousness is considered emerging on the basis of an informational reflection of reality. The author proves that building instruction on the basis of modular technology ensures the organization of the educational process in accordance with the nature of the activity of the cognizing subject, creates fruitful prerequisites for his selfdevelopment.

Problems and facts of structuring the content of special majors taught at the Aviation Institute, with the modular organization of the educational process, are presented by V.M. Gareev, S.I. Kulikov and E.M. Durko [2]. The attention of researchers in the theory of instruction is attracted by the laws of designing the content of instruction recognized in foreign theory and practice of modular technology. So according to V.P. Lapchinsky in secondary schools in England, the design of educational material, created on the principle of modularity, has the integration of various types and forms of learning, which is presented as a condition for each student to achieve their didactic tasks [6].

N.D. Nikandrov, analyzing the experience of using modular training in foreign universities, connects the positive effect obtained as a result of such training with the flexibility of modular technology - the variability of educational elements and modules. By means of modular technology individualization of training is achieved, the possibility of an individual pace of educational activity and, as a result, high learning outcomes [16].

Based on the experience of work of a foreign higher school in the mode of modular training, I.B. Martinkowski notes, as a significant positive factor, each student's awareness of the learning prospects presented by targeting in each module. Moreover, the need for differentiation of 
learning objectives into integrated and private [12] is indicated.

M. Lange associates the effectiveness of modular training with the introduction of a system of questions, exercises, and tasks into the structure of the module in order to master the educational material presented in each educational element [13].

\section{RESULTS}

Theoretical development and experimental verification of the concept of ensuring the effectiveness of teaching general disciplines through the use of modular learning technology convinces that the strategic direction is a set of measures identified by this dissertation research. Moreover, these measures are based on scientific and pedagogical methods. The essence of educational problems is of anthropic nature, and, therefore, to solve them, socio-psychological and didactic methods are necessary, and in general methods of scientific pedagogy are needed. It must be emphasized that the basis for solving this problem does not seem to be the use of expanded material resources, but due to the introduction of existing and proposed provisions of pedagogical science into the practice of teaching.

The specifics of pedagogical science is such that its theoretical principles cannot be directly used by the teacher in his daily work. A tool is needed to transform the psychological and pedagogical provisions into the norms of practical activity of a teacher. Such a tool in education can be recognized as the proposed concept of using technology of modular learning, which acts as a means of practical implementation of the achievements of pedagogical science, translating scientific provisions into the language of practical pedagogical actions.

The work performed allows us to formulate the following conclusions.

1. The results of theoretical and experimental studies give reason to argue that the effectiveness of the use of modular learning technology in teaching general disciplines can be achieved if a complex of scientific, pedagogical and philosophical knowledge is laid on the basis of its structurallogical scheme, the main components are the following:

- the principle of the integrity of the pedagogical system with the harmonious interaction of its components achieved due to the presence of effective feedback - monitoring, the results of educational activities of students;

- goal-setting as the basis for managing the process of cognition. Learning objectives are presented through the types and methods of educational and professional activities. A specific and diagnostic description of the goals makes it possible to use them as a guideline for selecting the contents of the modules. At the same time, didactic goals act as a kind of guide from which students will learn what are the requirements for their training. Initially, the goal of training is formulated by the developer of a modular program and, in relation to the student, acts as a quasi-target.

- an active approach not only to the educational process, but also to the content of education, focused on revealing the activity structure and the genesis of taught knowledge;

- reflective-critical equipment of the educational process;
- the correctness of the logic of structuring the quasiprofessional activity of students is achieved through the widespread use of schemes of an indicative basis for action;

- a contextual approach to the content of educational information and the organization of the educational process, ensuring the acquisition by future specialists of subjectprofessional and social experience;

- the convergence of the motivational needs of students with the structure and substantive organization of the learning process;

- individualization and personalization of training;

- intensification of the educational process due to motivation and visualization of educational information, as well as the widespread use of computers;

- the formation of a system of motives for educational and cognitive activity of students and the creation of pedagogical conditions for their transformation from achievement motivation through cognitive motivation to professional motivation;

- constructive mechanisms of the theory of selforganization (synergetics), which determine the conditions for the emergence and maintenance of a stable state of the phenomenon of self-organization of educational and cognitive activity of students;

- humanization of the learning process, as a result of which the student and teacher are in the subject-subject interaction.

\section{DISCUSSIONS}

The effectiveness of the implementation of modular learning technology is expressed in the guaranteed achievement of the current level of professional competence of students. The leading didactic conditions are to recreate in classroom conditions in a didactically transformed form of production fragments and professional relations of specialists working in the field of education. The forms of the problem lecture and the lecture-discussion allow us to recreate the process of interaction of specialists discussing theoretical issues. The subject and social contexts of the professional future of students are realized in laboratory work, in the structure of which simulation and game models are introduced. Active formation of the content of education by students themselves is achieved during the implementation and defense of term paper, in practical exercises, while the simulation object is the subject basis of a fragment of quasi-professional activity, the implementation of which requires the systematic application of various knowledge and skills, which creates the necessary conditions for the gradual transition of cognitive Type of activity in a professional. Traditional forms of training in the conditions of modular technology do not lose their properties and capabilities. Their use provides a gradual, natural transition from a purely educational activity of 
students through quasi-professional to professional.

Modular teaching technology is based on the general theory of functional systems, neurophysiology of thinking, pedagogy and psychology.

Research in these areas shows that the human brain, with its modular texture, responds best to quantum information (in other words, certain contributions).

Modular training provides an opportunity to solve the following modern issues of vocational education:

- Module - optimization and systematization of contentbased learning content, ensuring flexibility of programs;

- individualization of training;

- Monitoring the effectiveness of training at the level of practical activities and observing the evaluation of observable actions;

- Activation of the teaching process based on professional motivation, full realization of the independence and training opportunities.

Within the framework of different concepts, modular training programs, including different content and structures, are presented in various forms, but they all contain the following three main components: the targeted content program; Bank of information provided in various forms; methodical instructions for students.

Principles of Modular Learning

Modular learning technology is developed and implemented according to accepted principles of training (Figure 1).

The following principles form the basis of modular learning technology:

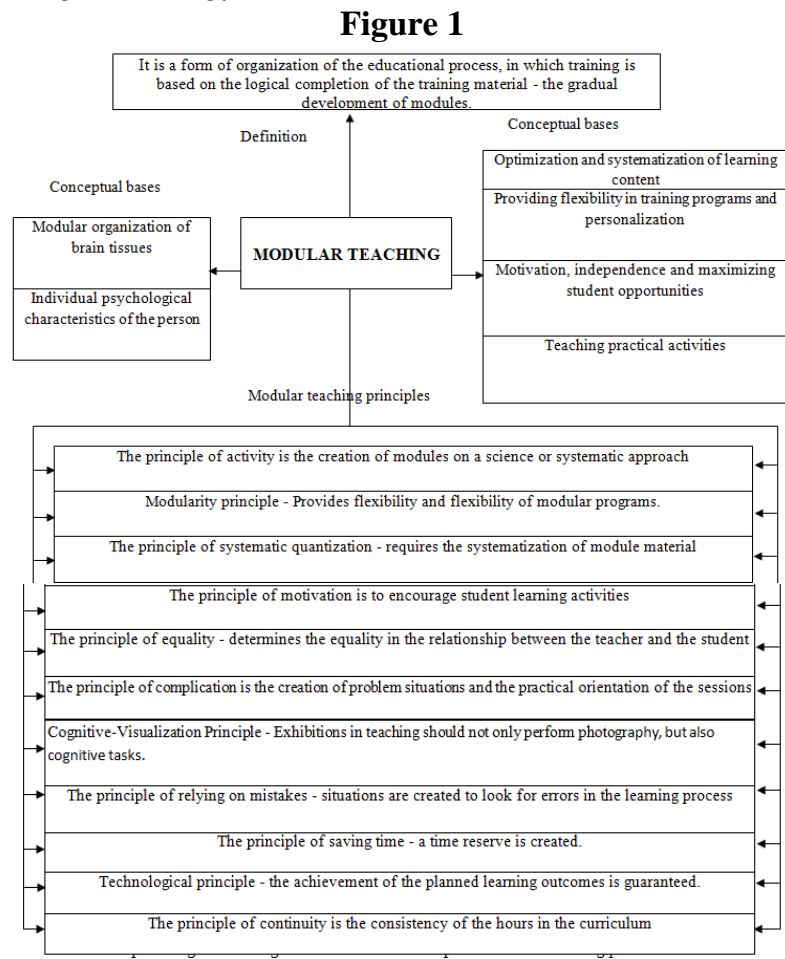

Figure 1. Block diagram of modular teaching

"Compression" of educational information based on the principles of modular learning in the learning process;

Optimizing the training schedule based on 'compression' of the training period.
1. The principle of action: This principle means that the modules are formed according to the content of the specialist's activities.

Under this principle, the modules can be structured based on a science activity or a systematic approach. The approach to science activities in modular learning technology requires the development of modules as a result of curriculum and program analysis. In a systematic approach, the module block is based on an expert's professional performance analysis.

2. The principle of equality. This principle determines the nature of the subject-subject relationship between the teacher and the student.

It means that modular learning technology belongs to the category of personalized technologies. In other words, modular learning technology is adapted to the individual psychological characteristics of the individual.

The organization of the learning process can be viewed as an integral part of the modular learning system.

One of the features of the modular learning system is the acceleration of the learning process, which can be explained in two aspects.

The most effective form of organization of the educational process is the weekly module planning of lessons and rating of knowledge of students. That is, one module (2-3 lectures and their practical and laboratory work) should be scheduled for one week, which should be completed by assessing student knowledge through tests or other forms of control.

The following benefits from the content of the module:

- ensuring continuity of learning between modules and interdisciplinary modules;

- establishment of methodological justifications for all types of training within each module and between them;

- flexibility of the module structure of science;

- regular and effective monitoring of students' knowledge (after each module);

- stratification according to the students' immediate abilities (after the initial modules, the teacher may recommend individual students to master the subject);

- Optimizing the hours allocated for lecture, practice (practice), individual and independent work as a result of "compression" of information, accelerating learning, effective use of classroom hours, and classroom content. As a result, the learner will have sufficient knowledge, skills and qualifications.

The modular learning technology based on the sciencebased approach is implemented through pedagogical and technological maps developed for each module.

Conclusions and Recommendations

Thus, training of highly qualified specialists using module training is provided on the basis of: 
- Continuity of teaching (which increases the effectiveness of learning subjects);

- Accelerated learning as a result, much of the information is absorbed through computer networks, both individually and independently;

- individualization of learning (the learner will have the opportunity to learn according to his abilities).

Providing sequential mastering of modules designed for a particular subject, taking into account the activities of an expert is the essence of modular teaching technology based on a science approach. Optimization of this learning process allows adaptation and individualization of teaching.

So, modular training programs can be composed of modular blocks and training modules that are needed for a particular workplace for a particular situation. The advantage of this program is that it provides training modules in the system of teacher training and retraining.

Modular training programs can be supplemented with new modular blocks and training modules, which will play an important role in the development of new technologies. This program is a flexible training program document that can be upgraded as technology, equipment, tools and materials improve.

The process of implementing a modular training program will consist of the following steps:

- Training is carried out in the form of individual modular programs, independent, step-by-step learning. At the same time, each student is provided with a training module, the conditions for acquiring theoretical knowledge and practical skills.

- Step-by-step monitoring of knowledge and skills development. The training modules are designed for each level of qualifications, so the formation of knowledge and skills is carried out on a continuous basis for each qualification, using control tasks, questions and tests.

In teaching modules, the main tasks of a teacher are: Coordinator, Counselor, Supervisor.

Modular learning programs are easily adapted to the individual needs of the learner and have a free time factor, as the individualized learning process prevails here. The time required to master the modular learning program will depend on the student's natural abilities.

It is based on a systematic approach ensures effective teaching of the specialty, as it provides the opportunity for individual and independent learning of teaching material.

The educational process, organized by the technology of modular learning, provides the implementation of studentcentered learning. At the same time, each student, taking into account his abilities, inclinations, value orientation, has the opportunity to realize himself in educational activities through the use of alternative "learning paths". With modular technology, the content of education and its means allow the student to show selectivity for subject material, its type and form. Modular technology allows you to develop and effectively implement individual training programs. With the modular organization of the educational process, individual and group work of students is expediently combined, study time is rationally and economically used, each student can move forward in his own temporary key. The value of the technology of modular learning as a means of implementing a personality-oriented education is based on the fact that the achieved education, represented as a combination of knowledge, skills and abilities (according to V.V.Serikov), is the most important condition for the formation of social and intellectual qualities of a specialist's personality .

One of the main advantages of modular learning technology is the activation of student learning activities. We believe that the process of enhancing educational activity is based on value orientations, which are largely formed precisely by the technology of training, in this case, modular technology through rating control of the level of knowledge and skills. Under value orientations, in accordance with the definition given by N.V. Ivanova, we understand the system of individual aspirations, as well as its ideas about the meaning of activity, which is the internal source of student self-activity. Value orientations express a concrete understanding of the goals of an activity. On their basis, prestigious preferences and corresponding behaviors are formed.

The technology of modular teaching instruction, providing a mechanism for the formation of students' value orientation, positively affects their behavior, being the basis of activity. An essential element of modular learning is the dynamics of value orientations. Experience in the modular technology mode shows that students gaining a certain number of rating points in the first module, then moving along the module program from module to module, actively seek to increase their rating. The perception and understanding of the teaching material of a general discipline requires a great intellectual effort from the student. And, as a result, with any teaching technology, there is a value contradiction expressed in the contrast of different values: on the one hand, the student seeks to protect himself from high energy costs associated with intense mental work; on the other hand, there is a desire to receive a high-quality professional education. Thus, a value contradiction is experienced and recognized by the individual as the difficulty of choosing and making a decision. Tracking the real educational process, organized by modular technology, allows us to argue that this type of training technology provides a solution to the value contradiction in favor of high-quality education. Modular technology creates the possibility of value-oriented activities of students, represents the means for the implementation of their value orientations.

The proposed organization of the learning process provides a transition from individual, unsystematic, disparate fragments of active learning to their system within the framework of pedagogical technology. The use of the concept of modular training in education is not just the design of educational material in a module, it is a systemforming factor at such a level of organization of the educational process at which its integrity, controllability, and the guarantee of obtaining the planned learning result are achieved. The proposed pedagogical teaching technology is considered by us as an integral (procedural) part of the didactic system of modular training. Its belonging

Published By

Blue Eyes Intelligence Engineering 
to the category of pedagogical technologies is confirmed by a number of characteristics typical for them (V.P. Bespalko, B.S. Bloom, V. Klarin, I. Marev): reproducibility, feasibility, efficiency, controllability, cost-effectiveness, correctness tirimosti. Using the proposed training technology allows you to turn the process of teaching a general discipline into a kind of production and technological process with a guaranteed result - achieving a clearly defined level of specialist competence.

However, there are some problems with the organization of modular training. It is necessary to avoid the mechanical breakdown of the "indivisible" training material into doses in accordance with the modules. The development of a large number of individual training programs in many ways can put the teacher in a difficult position.

It should be noted that the main difficulty in implementing the created concept of using modular technology was expressed in the inertia of the prevailing stereotypes of traditional education. The traditional pedagogical system of education is inherently very conservative. The main custodians of the conservatism of the system are practical educators. Rebuild their activities this means to change their entire circle of professional consciousness. This is the main difficulty in introducing modular technology, despite the obvious effectiveness of the created conceptual and theoretical foundations. Nevertheless, the evolution of the pedagogical system is objectively logical. The technology of modular training is the result of the evolution of a professional training system. The modern stage in the development of didactics provides the status of a "polyphonic" didactic system for modular education, accumulating the advantages of integrating traditional and new pedagogical theories, which allow reaching a new qualitative level of solving pedagogical problems. Despite the fact that the theoretical principles of modular teaching technology are formulated quite clearly, we are convinced that the further evolution of this didactic system is possible by improving its psychological, pedagogical and scientific-methodological support, not distorting, but generalizing and developing the concept of modular teaching.

\section{CONCLUSIONS}

At present, the university has been put in the position of a service market subject by socio-economic conditions. In this market, distance learning is gaining great popularity. The technology of modular learning fits perfectly into the scheme of organizing distance learning.

Distance learning is economically and socially feasible right now, in the context of the formation of a market that forms a certain contingent of potential users. These include those wishing to get an education in an additional specialty; employees of various public and private organizations undergoing retraining and advanced training; correspondence students. As you can see, the students in the distance learning system are adults. Moreover, the use of pedagogical principles worked out in the process of teaching children and adolescents seems to us inappropriate. Therefore, as a fruitful direction in the development of the scientific and pedagogical concept that we offer, we see the further development of the theoretical foundations of the technology of modular learning, taking into account the principles of andragogy - a new branch of human science that considers the specifics of adult learning.

General educational disciplines are characterized by a high level of information saturation. Relevant are the problems of compiling knowledge, developing procedures for verifying its correctness and operational use. In this regard, in our opinion, it may be promising to use the concept of knowledge (the term E. Feigen Baum) as an extension of the methodological basis of the technology of modular teaching to general disciplines. Knowledge is an area in the theory of artificial intelligence, which contains as the main tasks the development of models for the representation of knowledge, methods for supplementing and processing it. Despite the fact that teaching FL refers to the training of intelligent systems, we believe that its main provisions can be extended to human learning. The creation of intelligent systems relies on the use of an analogy of the neutron structures of the human brain. In addition, a person acts as a user of intelligent systems. Thus, both in the creation and in the application of intelligent systems, the mechanisms of human learning are taken into account.

The success of introducing modular teaching technology into the pedagogical reality of a university requires the development of appropriate psychological support for this innovation. The lack of development of the theoretical aspect of the socio-psychological problem of the introduction of educational technology entails the rejection of changes by teachers and the unpreparedness of students for them. The creation of a theoretical model for introducing modular teaching technology into educational practice will contribute to the formation of the teacher's acme logical professional position, which determines the highest productivity of pedagogical activity.

\section{REFERENCES}

1. Bespalko A.P. Programmed Learning: Didactic Fundamentals. M., 1970, p. 300.

2. Gareev V.M., Kulikov S.I., Durko E.M. Principles of modular education // Bulletin of higher education. 1987. No. 8. P. 917.

3. General course of higher mathematics for economists: a textbook / Ed. IN AND. Ermakova. M., 2007. P.656

4. Kupisevich Ch. Fundamentals of general didactics // Transl. from Polish, M., 1986. p. 367

5. Landshaer V. The concept of "minimum competence" // Prospects: educational issues. 1988, No. 1. - P. 27 - 34.

6. Lapchinskaya V.P. Secondary school of modern England, M., 1977-216 p.

7. Lavrentiev G.V., Lavrentiev N.B. Components of modular learning technology Barnaul Publishing House of Altai University, 1994. p. 128.

8. Lavrentieva N.B. On the introduction of modular education in the university pedagogical system // Abstracts of reports of the interuniversity conference "Modern problems of activating creative abilities in the process of training engineers." Barnaul, 1993 .-- P. 34 42. 
9. Lavrentieva NB From the experience of introducing a modular training system at the faculty of engineering // Bulletin of the UNMO of Russian universities in engineering and pedagogical education. Yekaterinburg, 1993.P. 34-48.

10. Lavrentieva NB The pedagogical foundations of the development of modular training technology. Barnaul, Alt.GTU Publishing House, AltAEP, 1998 .-- 252 p.

11. Mamrak A.V. Programmed teaching in the Russian language classes in the context of the restructuring of higher education // Republican Interdepartmental Scientific Collection. Programmed training. Issue No. 27.1. Kiev, 1990. P. 7.-12.

12. Martsinkovsky I.B. University education in capitalist countries. Tashkent, 1981. $190 \mathrm{p}$.

13. Mikhailova I.G. Mathematical training of an engineer in a professional orientation of intersubject communications: Diss. . Ph.D. Tobolsk, 1998. P.221

14. Moroz O.V. Professionally oriented design of didactic support of a mathematics course for the specialty "Regional Studies": Diss. . Ph.D. Krasnodar, 2007. P.235

15. Nemov P.C. Practical Psychology: Knowing Yourself: Influencing People: A Manual for Students. M., 2001. P.320

16. Nikandrov N.D. Modern higher school of the capitalist countries. The main issues of didactics M., 1978. 279 p.

17. Pedagogy. Study Guide for Stud. ped universities and ped. colleges / Ed. P.I. Fagot. M., 2004. P. 608

18. Pidkasisty P.I. Independent cognitive activity of schoolchildren in learning. M., 1980.240s.

19. Prigogine I. Nature, science and new rationality. M., 1983 p. 243.

20. Theory and practice of pedagogical experiment / Ed. A.I. Piskuno-va, G.V. Vorobyov. M .: Pedagogy, 1979.- 208 p.

21. Vazina K.Ya. Human self-development and modular support. N. Novgorod, 1991. -174 p.

22. Woolridge D. Mechanisms of the brain. M .: Mir, 1965. P.148.

23. Yub. Sennovsky I.B. Modular pedagogical technology at school: analysis of the conditions and results of development, M., 1995. P.123. 